\title{
Des-indianización y etnicidad evangélica en el piedemonte y el altiplano andinos de Jujuy. Una etnografía histórica
}

\section{( Mariana Espinosa*}

\author{
Fecha de recepción: 15 de mayo de 2020. Fecha de aceptación: 13 de octubre de 2020
}

Palabras clave etnicidad evangélica etnografía histórica Jujuy

\section{Key words \\ evangelical ethnicity historical ethnography Jujuy Province}

\section{Resumen}

El artículo propone una etnografía histórica y comparativa sobre la primera expansión evangélica en el piedemonte y el altiplano andinos de la provincia de Jujuy, Argentina. Aunque en condiciones ecológicas y demográficas distintas, esta expansión evangélica ocurrió durante la primera mitad del siglo XX como parte del mismo proceso, en tanto fue impulsada por una corriente misionera de origen británico y posteriormente por evangelistas indígenas, en los marcos de la construcción del Estado Nación y de las economías de enclave -azucarera en el piedemonte, minera en el altiplano. El argumento central es que el encuentro de poblaciones guaraníes y collas con esta nueva religión, y el proceso de adopción de la misma, operó tendiente a un proceso de desindianización y hacia la configuración de una etnicidad evangélica.

\section{De-indianization and evangelical ethnicity in the foothills and the Andean highlands of Jujuy. An historical ethnography}

* Investigadora del Consejo Nacional de Investigaciones Científicas y Técnicas, Instituto de Antropología de Córdoba y profesora en el Departamento de Antropología, Universidad Nacional de Córdoba. Córdoba, Argentina. E-mail: marianaestherespinosa@gmail.com 


\section{Introducción}

A lo largo del piedemonte andino de las provincias de Salta y Jujuy, en zonas urbanas, periurbanas y rurales, es posible observar cuantiosas iglesias evangélicas cuyos miembros en su mayoría se adscriben como guaraníes, ava-guaraní o reconocen dicho origen en sus antepasados. Asimismo una visita, no precisamente turística, por la Quebrada de Humahuaca y la Puna también daría cuenta de variadas iglesias evangélicas entre los pueblos y ciudades que conectan dicha región. En este caso se trata de grupos que se adscriben como collas, andinos, comunidad aborigen, entre otras posibilidades.

Fueron misioneros y misioneras, vinculados al movimiento evangélico británico conocido como Plymouth Brethren, Christian Brethren o Hermanos Libres en Hispanoamérica, quienes a fines del siglo XIX y principios del siglo XX iniciaron experiencias de misionalización entre guaraníes al interior de un ingenio azucarero llamado La Esperanza, del cual surgieron decenas de iglesias y obras misioneras a lo largo del piedemonte andino y del occidente chaqueño. Aunque en condiciones ecológicas y demográficas diferentes, el establecimiento de las primeras iglesias evangélicas en la Quebrada de Humahuaca y la Puna de Jujuy forma parte del mismo impulso misionero y se realizó en condiciones económicas análogas; en este caso, el desarrollo de las grandes explotaciones mineras a partir de la década de 1930.

No desprovista de un sesgo católico-céntrico y una mirada estática de las identidades étnico-religiosas, ${ }_{1}^{1}$ la antropología prácticamente ha ignorado este fenómeno. Lo cierto es que en ambas subregiones estos grupos se reconocen como evangélicos y tienen consciencia de formar parte de colectividades que preexisten a la sociedad colonial y al Estado Nación, y que fueron afectadas por acciones y representaciones de racialización. De la misma forma, conservan en su memoria colectiva nociones y experiencias sobre el contacto entre sus antepasados y los misioneros, en el marco de su incorporación a un régimen de trabajo basado en la explotación humana, cuya organización y jerarquías también respondía a patrones de esencialización de sus diferencias desde un punto de vista civilizador.

El presente artículo busca profundizar en la comprensión de la adopción de la propuesta evangélica británica por parte de estos grupos, prestando atención a las relaciones, representaciones y prácticas socio-históricas en tanto vehiculizaron la reelaboración étnica. Esto implicará poner en movimiento una perspectiva relacional e histórica de las configuraciones étnicas, raciales y de clase, a partir de la restitución bibliográfica, documental, etnográfica y comparativa de una serie de acontecimientos y representaciones significativas sobre el contacto entre indígenas y misioneros, lo que nos remontará preponderantemente a la primera mitad del siglo XX. ${ }^{2}$

En primera instancia, nos detendremos en algunos elementos teóricos a fin de pensar las interacciones entre grupos étnicos y religión. Después, daremos cuenta de la llegada de los misioneros a estas subregiones al momento del despegue de las economías de enclave, y de la situación de los grupos indígenas al momento de entablar contacto con los primeros. Esto permitirá avanzar hacia un análisis de los factores push (presión) y pull (atracción) en la adopción de una nueva religión y en los procesos relacionales de reconstrucción de la identificación étnica. El argumento da relieve a la manera en que la adhesión a la propuesta evangélica fue concomitante con un proceso de des-indianizacion; es decir, al intento de desprendimiento de marcadores raciales impuestos y
1. Entre los antropólogos argentinos, tempranamente Pablo Semán (2006) se refiere al modernocentrismo como un sesgo epistemológico para acceder y comprender la singularidad de las elaboraciones socio-religiosas de sectores populares bonaerenses. Alejandro Frigerio (2007) también advierte sobre el uso metonímico de nociones como creencia e identidades religiosas y la necesidad de profundizar en estas últimas para evidenciar las maneras estáticas de considerarlas. Sin embargo, a pesar de que estas y otras críticas han tenido impacto entre los estudios sobre religiosidades de sectores medios y populares urbanos de la Argentina, los principios de esta misma postura encuentran mayor resistencia cuando se trata de abordar creencias y prácticas socio-religiosas entre pueblos originarios. A excepción del corpus bibliográfico que compone la Etnografía Chaqueña -dos síntesis de estos estudios pueden encontrarse en Wright (2002) y Ceriani Cernadas y López (2017)- los estudios reportados sobre otras áreas culturales indígenas obliteran o no problematizan suficientemente la presencia evangélica, pasada o presente. Signo de esto son los escasos antecedentes académicos sobre la presencia evangélica en los Andes, en donde encontramos el clásico estudio de Rita Segato (2007a) sobre la expansión evangélica en la Puna y el trabajo de Claudia Lozano (2001) focalizado en la Quebrada de Humahuaca.

2. El registro de campo que utilizaremos refiere a una etnografía más amplia desarrollada entre comunidades guaraníes -o de origen guaraní- de La Esperanza, San Pedro, San Martín (Ledesma), Tartagal y Aguaray entre 2013 y 2016 , y entre grupos originarios de Tilcara, Abra Pampa y Casa Colorada entre 2017 y 2019. En el primer caso se trata de la subregión del pie de los Andes y el borde más occidental del Chaco Salteño. En el segundo caso de la Quebrada de Humahuaca y la Puna de Jujuy El trabajo de campo se desarrolló en el marco del proyecto de investigación PICT-FONCyT "Evangelismos, mediaciones culturales y relaciones interétnicas en el Noroeste Argentino", radicado en el Instituto de Antropología de Córdoba (UNC-CONICET). 
hacia la forja de una etnicidad evangélica, no sólo motivada por la atracción y apropiación de una cultura misionera sino por efecto de las tensiones implícitas en representaciones dominantes y en una estructura de interacción que, en determinadas circunstancias, activaron la autoafirmación.

\section{Grupo étnico y cambio religioso}

A principios del siglo XX, Max Weber ofreció una visión del grupo étnico no necesariamente remisible a la "raza" e incluso escindida de caracteres biológicos; acentuaba la creencia subjetiva en una procedencia común, el agrupamiento unido a alguna motivación política o religiosa y como efecto de oposiciones respecto a otros grupos (Weber, 1964: 315, 318, 319). Además, en relación a la existencia de una "verdadera comunidad de sangre", el sociólogo alemán señaló, entre otras cuestiones, que la tendencia a la endorreproducción -es decir, la restricción al connubio de los descendientes del mismo grupo socialresponde más a factores estrictamente culturales -estamentales, políticos, de culto o económicos- que a la mera "afinidad racial objetiva" (Weber, 1964: 316). Compartiendo lo esencial de este planteo, Frederik Barth (1976) enfatizó la idea de que los grupos étnicos son categorías de adscripción e identificación utilizadas por los propios actores. Asimismo, expandió el aspecto relacional de la definición: de acuerdo a Barth el establecimiento de este límite social entraña en un mismo sujeto la coparticipación de criterios de valoración entre miembros del mismo grupo y, por otro lado, el reconocimiento de limitaciones para llegar a un entendimiento con otro grupo. Por tal motivo, la persistencia de los grupos étnicos en contacto implica no sólo criterios y señales de identificación sino que también supone una estructura de interacción. Los aspectos culturales que moldean los límites pueden cambiar, pero la producción de diferencia permanece mientras subsista la dicotomía entre 'miembros' y 'extraños' (Barth, 1976).

La identificación étnica, como señaló Weber, también emerge en "recuerdos de colonización y migración" (Weber, 1964: 318). Jean y John Comaroff (1992) llevaron más allá este aspecto indicando que, a diferencia del totemismo, la etnicidad es producto de procesos históricos que estructuran relaciones de desigualdad. Dicho de otro modo, la etnicidad deviene de una específica articulación entre grupos en la que uno extiende su dominio sobre el otro. La doble naturaleza de la conciencia étnica -el hecho de que involucra la afirmación del propio colectivo como la negación de los otros- es una expresión del estructuramiento de la desigualdad (Comaroff \& Comaroff, 1992). Como es sabido, los grupos sociales son propensos a envolverse en procesos tendientes a inhibir o revertir los marcadores que determinan relaciones de desigualdad. Esto alberga una contradicción fundamental. De acuerdo a Jean y John Comaroff, cada acción orientada a revertir tales desigualdades podría reforzar la primacía de la etnicidad como principio de diferenciación social. Así entonces la etnicidad podría ser perpetuada por factores diferentes a los predominantes en tiempos pretéritos (Comaroff \& Comaroff, 1992).

Nos interesa retener otras cuestiones también indicadas por Weber ya que, junto a las ya señaladas, son operativas para pensar las interacciones entre grupo étnico y religión. Para el sociólogo alemán “el grupo étnico no es en sí mismo una comunidad sino tan sólo un 'momento' que facilita el proceso de comunalización" (Weber, 1964: 319 y 320). En este sentido, además del lenguaje, la vida ritual y las representaciones religiosas siempre constituyen elementos activos en la creación de un sentimiento de afinidad étnica. A esto podemos 
sumar la importancia de las "diferencias externas" para la formación del grupo étnico "tales como la de los vestidos típicos, la vivienda, la manera típica de alimentarse, el modo de división del trabajo entre los sexos" (Weber, 1964: 319 y 320). No es posible ignorar que las nuevas ofertas religiosas ofrecen no sólo ritualidad sino diversos artefactos que en su apropiación pueden actuar, entonces, como vehiculizadores de agrupamiento o reavivamiento étnico.

En esta dirección Paula Montero, refiriéndose a las relaciones entre misioneros e indígenas, considera a lo religioso como "lenguaje privilegiado de las relaciones interculturales", puesto que produce las categorías por medio de las cuales los agentes responden a situaciones que suscita el contacto (Montero, 2006: 11). En este sentido comprender el universo de relaciones entre misioneros, indígenas y otros agentes en tanto relaciones de mediación, supone que las mismas están marcadas por estrategias de traducción y códigos compatibilizadores. Pensar las acciones en tanto mediaciones "supone un misionero que se comunica con la diferencia nativa y, al mismo tiempo, un nativo que se apropia en parte de esas representaciones de sí y las reconfigura" (Montero, 2006: 25).

De acuerdo a Rita Segato, ciertas religiones "forman parte del flujo de bienes culturales que se globalizan". En ese tránsito su reelaboración se produce en el marco de "la frontera -política y simbólica- de la Nación pero también a la sombra y bajo la influencia de la gran frontera Norte/ Sur" (Segato, 2007b: 179-180). En este sentido los bienes religiosos son percibidos desde el Sur cargoísticamente; esto es, cargados de elementos novedosos que distinguen y diferencian. Sentimientos de prestigio se ponen en juego en la adopción de nuevas propuestas religiosas entre grupos locales, pero también sentimientos de inclusión y acceso a patrones de conductas e ideas modernas. En cuanto a la frontera entre la Nación y sus Otros, la autora indica que:

\section{La tensión entre la Nación con voluntad unitaria por un lado, y la pluralidad fundada por ese encuentro interétnico, por el otro, es constitutiva de esas naciones, siendo la estructura de estas relaciones la que proporciona un lenguaje o modelo para incorporar la presencia de otros componentes como las opciones religiosas particulares (Segato, 2007b:183).}

De acuerdo a Segato, y bajo el prisma socio-histórico de la Nación y de la frontera Norte y Sur, los nuevos contenidos religiosos son resignificados al tiempo que los contenidos originarios se resimbolizan. Las nuevas identidades religiosas se internacionalizan y se autoctonizan, lo que a su vez puede devenir en procesos de re-etnización o des-etnificación para los pueblos originarios (Segato, 2007a). Estas ideas refieren principalmente a dos investigaciones etnográficas de la autora. En un caso, a la expansión de cultos afro-brasileros en la Argentina y su adopción por diversos agentes, con o sin pertenencia a la población africana o afroamericana pero con voluntad de minoría en tanto agentes marcados negativamente por su origen, entendiendo este proceso como de re-etnización (Segato, 2007c). El otro caso, refiere justamente a la expansión evangélica en los Andes -Puna de Jujuy-, donde la autora señala movimientos de re-semantización y re-simbolización concluyendo que "estos procesos constituyen aspectos de una tendencia general hacia la des-etnificación en lo que respecta al repertorio cultural, pero a la continuidad del grupo étnico como unidad social" (Segato, 2007a: 206). ${ }^{3}$

Teniendo en cuenta la propuesta del presente artículo de contribuir desde una mirada histórica, etnográfica y comparativa de dos zonas demográficas y ecológicas disímiles del NOA, y reteniendo el presupuesto de que la configuración
3. El momento socio-histórico de la etnografía define el tipo de fenómeno frente al cual el antropólogo/a se encuentra. En este sentido es importante puntualizar que Rita Segato desarrolló su trabajo de campo en 1987 en Tilcara, Humahuaca, Villa Jueya, Susques, Coranzulí y el Toro. Como indiqué más arriba, parte del material vertido sobre la Puna pertenece a una etnografía reciente y a un recorrido por otras localidades y comunidades. Entre otras cuestiones la emergencia del Estado Plurinacional en Bolivia y la incorporación del Derecho Indígena en la modificación de la Constitución Nacional de la Argentina sin duda influyeron en el desenvolvimiento de los grupos evangélicos andinos en cuestión. 
4. La composición y dinámica de esta nueva estructura agraria fue ampliamente estudiada. Algunos de los temas que destaca la bibliografía aluden a: la ausencia de regulación legal, la captación y retención coercitiva de mano de obra, la formación de un mercado de explotación laboral, la migración y el conflicto interétnico (cfr. Campi, 1992; Lagos, 1992; Santamaría, 1992). de un grupo étnico se asocia predominantemente a factores culturales y relacionales, mi lectura del fenómeno será diferente. En el último aparatado intentaré recoger y explicitar los elementos socio-históricos de mi argumento, según el cual el encuentro o interacción de las poblaciones guaranies y collas con una nueva religión y el proceso de adopción de la misma operó tendiente a un proceso de desindianización -es decir, al intento por parte de estas poblaciones de desprenderse de marcas de racialización atribuidas violentamente en diversos contextos- $y$ hacia la configuración de una etnicidad evangélica, no sólo moldeada y motivada en las relaciones de mediación cultural sino por efecto de las tensiones y jerarquías inherentes en los formadores de alteridad como la Nación y otras configuraciones de escala local que, en determinadas circunstancias, activaron y/o reforzaron fronteras para la autodefinición en relación a otros.

\section{La expansión evangélica en el piedemonte andino entre grupos guaraníes}

A finales del siglo XIX y principios del XX, en el marco de la conquista militar del Gran Chaco y la extensión del ferrocarril a Salta y Jujuy, se inició una nueva etapa para los establecimientos azucareros del piedemonte andino y del occidente chaqueño. El Ingenio La Esperanza, antiguo establecimiento ubicado sobre el valle del Río San Francisco, fue bautizado en 1833 con ese nombre por sus nuevos dueños, la familia inglesa Leach; de la mano de sus miembros sobrevino la llamada modernización de este y otros ingenios del piedemonte. La mecanización de los antiguos trapiches favoreció la extensión de los cultivos de caña y la demanda de grandes contingentes de trabajadores y trabajadoras. Llegaron indígenas, mestizos y campesinos de las más diversas regiones: Quebrada de Humahuaca, Puna, Gran Chaco, Yungas, etc. tanto de Argentina como de Bolivia. ${ }^{4}$

Los grupos guaraníes que arribaron a los ingenios correspondían principalmente a los llamados chiriguanos, grupo derivado de la unión tupi-guarani y arawak (chané) ocurrida en el siglo XVI en territorios del oriente boliviano (Combés \& Saignes, 1991). A principios del siglo XX, el etnógrafo sueco Erland Nordenskiöld señalaba que:

los indios que viven en Bolivia llaman a la Argentina Bapurenda que significa: allí hay trabajo. Cada año vienen miles de indios del Chaco argentino y de Bolivia a las fábricas de azúcar para buscar trabajo. Se los emplea tanto para rozar y labrar, como para cosechar [...] (Nordenskiöld, [1912] 2002: 4-5).

Fue el imaginario de Mbporenda -la tierra del asombro, del trabajo, de la abundanciaaquello que antepusieron idealmente los ingenios del Noroeste Argentino a la explotación laboral en las haciendas bolivianas y al creciente acorralamiento territorial de los militares y la población criolla (Langer, 1995). De acuerdo a Silvia Hirsch los chiriguanos que migraban a la Argentina eran aquellos que para entonces vivían en misiones franciscanas y, en consecuencia, tenían un mayor conocimiento del castellano, estaban familiarizados con el trabajo asalariado y habían asistido a la escuela (Hirsch, 2004). Reconstruyendo trayectorias de pobladores guaraníes que actualmente viven en La Esperanza y San Pedro, además del origen de sus antepasados en el oriente boliviano, también algunos de ellos habrían llegado desde el Paraguay huyendo de la Guerra del Chaco (1932-1935). 
A diferencia de los indígenas del Gran Chaco, que eran trabajadores temporarios de la zafra, los chiriguanos mayormente se encontraban en planta permanente no especializada y habitaban en casillas contorneando los lotes, lugar donde se plantaba la caña. Existía una correspondencia entre jerarquía étnica, estratificación laboral y espacialidad, en cuyo escenario los chiriguanos habrían sido el grupo étnico mejor considerado por los patrones (Lago, 1992; Santamaría, 1992; Bossert, 2012). Las representaciones dominantes de la época trazaban una jerarquía interétnica basada en apreciaciones sobre el aspecto físico y las costumbres, y desde la cual se medía la capacidad de trabajo de los grupos indígenas en las economías de enclave (Bossert, 2012). ${ }^{5}$

El inicio de la expansión evangélica entre los guaraníes data de fines del siglo XIX, con la llegada del misionero John Linton al ingenio azucarero La Esperanza. En 1908 llegó el misionero Thomas Easdale quien contrajo matrimonio con Elisabeth Linton, hermana del anterior. Los dueños del ingenio dieron casa a los Easdale y tierras para establecer la misión al interior de la fábrica de azúcar, el lugar fue bautizado como cherenta -mi casa. Thomas y Elisabeth ministraron en La Esperanza y alrededores hasta la vejez. Además del recordado matrimonio, otros misioneros y misioneras acompañaron este emprendimiento y evangelizaron en el piedemonte y en el occidente chaqueño principalmente hasta 1950, año a partir del cual no se observa relevo. Entre estos podemos nombrar a Heycock, Leggat, Dickson, Woodhatch, Cook, Powell y Gerrard (Espinosa, 2017).

Estos misioneros pertenecían -o se enrolaron en el campo misionero-, al movimiento evangélico conocido como Plymouth Brethren o Christian Brethren, y en Hispanoamérica como Hermanos Libres, el cual surgió en el primer cuarto del siglo XIX en contraposición al clericalismo de las iglesias establecidas del Imperio Británico. Al igual que el protestantismo predominante en América Latina de fines del siglo XIX y principios del siglo XX, estos misioneros expresaban en la noción de caridad un genuino interés social por la población, pero sin una perspectiva política integrada a su fe (Miguez Bonino, 1995: 46). En la práctica esto implicaba una actitud de reforma social a través de la educación, como la iniciación en la cultura escrita en español, preceptos higienistas y una reforma moral mediante la transmisión del mensaje de salvación como única vía para superar situaciones de opresión. A la salvación le seguía la santificación; esto es, la demarcación de una nueva comunidad de pertenencia progresivamente apartada de los asuntos del mundo.

A mediados de la década de 1940, surgieron medidas que implicaron cambios sustantivos para las poblaciones bajo foco. En 1944 se promulgó la Ley 12.912, más conocida como el estatuto del Peón con la cual el Estado pasó a regular los contratos laborales. Entre otras cosas, se exigió a las empresas proveer alimentos a precio justo y viviendas y asistencia médica a los trabajadores. Como indica Rutledge (1987: 215) en relación con las patronales de Jujuy, sería ingenuo creer que aquellas cláusulas eran rigurosamente cumplidas. Pero es indudable que por entonces se inició una nueva etapa con mayor presencia y resguardo estatal.

En ese mismo período el Estado impulsó políticas de regulación de las expresiones religiosas. En 1948 se creó un registro de cultos no católicos que prohibió el funcionamiento de cualquier centro religioso que no estuviera inscripto. El Ministerio de Relaciones Exteriores y Culto debía, además de garantizar el libre ejercicio del culto, fiscalizar a las organizaciones e intervenir si fuera necesario (Bianchi, 2004; Catoggio, 2008). Este hecho se vislumbra con ambivalencias en
5. En esta dirección podemos encontrar la siguiente apreciación en las notas de Nordenskiöld: "aquí se ve a los limpios y despiertos chiriguano y chané, a los traidores e impertinentes toba, a los sucios y poco fiables mataco, a los choroti, siempre alegres y vagos. Algunos tapiete y ashlusla y han estado aquí a su vez, aunque los primeros se presentaron como toba y los últimos como choroti o mataco" (Nordenskiöld, [1912] 2002: 4-5). 
6. Podemos mencionar el caso de Misión Cherenta, comunidad guaraní ubicada en Tartagal. En 2013 recogimos el testimonio de Arsenia Romero, hija del entonces cacique Jacinto Romero quien impulsó el emplazamiento de la comunidad en sus actuales terrenos. Arsenia nos comentó sobre el trajinado trayecto de La Esperanza a Tartagal y los innumerables problemas de tierras que tuvieron hasta que en 1969 apareció un terreno e inmediatamente los paisanos fueron llamados a mudarse allí. En sus palabras: "Se hizo grande Cherenta, mi casa. Él le ha puesto "Cherenta", mi papá. Porque [...], cuando yo era chica, él asistía a la iglesia de Cherenta, ahí, en La Esperanza, que era una linda iglesia". Una investigación sobre la expansión evangélica en el largo plazo entre los guaraníes del piedemonte andino y occidente chaqueño puede encontrarse en Espinosa (2017). los recuerdos actuales de los guaraníes evangélicos cuando, por un lado, revelan cierto reconocimiento o legitimidad social asociada al Fichero y, por el otro, refieren al hostigamiento si no se observaban correctamente las normativas.

Por efecto de la creciente mecanización en las tareas agrícolas, a partir de 1953 la industria azucarera disminuyó la demanda de trabajadores (Rutledge, 1987: 252-154). La Esperanza no fue la excepción de aquella nueva fase; familiares descendientes de aquellos primeros chiriguanos quedaron librados a la discrecionalidad empresarial, sin gozar de títulos sobre sus viviendas y terrenos y con problemas económicos -en tanto desempleados- para viajar y reconectarse a la red de familiares dispersos a lo largo de los territorios que unen Yungas y Chaco en la Argentina y Bolivia.

Algunos de los testimonios informan que las comunidades guaraníes y evangélicas de Cherenta, 9 de Julio y de Yacuy, ubicadas en las ciudades de Tartagal y Aguaray -provincia de Salta- deben su origen a guaraníes que trabajaban y habitaban en el ingenio La Esperanza, y que se establecieron allí, tras fracasados intentos por llegar hasta sus territorios de origen en Bolivia. ${ }^{6}$ Otras familias se quedaron en La Esperanza y actualmente viven en barrios marginales. $\mathrm{Ni}$ los pequeños terrenos y ni las casas que ocupan hace más de un siglo les pertenecen. El acceso al agua y a la salud es precario. La educación bilingüe no existe. Los procesos de organización para la conformación de comunidades indígenas con personaría jurídica son recientes y fueron impulsados no sin dificultades. Lo que se palpa en La Esperanza es la lucha de unos pocos contra los relatos dominantes de estigmatización por la pertenencia u origen indígena.

\section{La expansión evangélica en la Puna}

En la Puna prehispánica de la actual provincia de Jujuy habitaban los casabindos y cochinocas integrados, a su vez, a un conjunto de pueblos semejantes como los lipes, los atacamas, los chichas y los apatamas (Palomeque, 2000: 91-92). Al inicio del siglo XX, el arqueólogo sueco Eric von Rosen escribió: "La escasa población de la Puna de Jujuy consiste casi exclusivamente en indios de habla quichua. Muchos de ellos descienden seguramente de las tribus en su tiempo sometidas al Inca, que ya vivían aquí al llegar los españoles a Sudamérica [...]" (von Rosen, 1957: 77).

Para entonces en el altiplano andino existía una estructura de haciendas de arrendatarios con ausencia de propiedades indígenas reconocidas. El campesinado estaba debilitado por los altos costos de los arriendos a los propietarios latifundistas, la obligación del llamado servicio personal y la alta presión fiscal a sus productos ganaderos (Teruel, 2005). Se trataba de una economía de subsistencia basada fundamentalmente en el pastoreo, en algunos lugares complementada con agricultura, explotación minera artesanal y la fabricación de tejidos y artesanías (Teruel y Gil Montero, 1996: 203). Este modelo económico, hasta entonces vinculado al circuito mercantil andino, fue perdiendo importancia frente al crecimiento de la industria azucarera de los Valles Centrales y Subtropicales (Teruel, 2005).

La transformación de la Puna en enclave económico minero es posterior al despegue de los ingenios azucareros, aunque se repiten algunos actores. En la década de 1930 se desarrollaron la mina El Aguilar de capitales norteamericanos y Mina Pirquitas de capitales nacionales e ingleses (González, 2014). Pichetti, uno de los descubridores del estaño en Rinconada, se asoció a los 
hermanos Leach del Ingenio La Esperanza, cuyo acuerdo fue conocido por las irregularidades en el catastro del terreno de la mina (Villafañe, 1938). Si bien en la Puna continuó un sistema de latifundios y arriendo, con las grandes explotaciones mineras los indígenas puneños tuvieron menos libertades y trabajar en las minas se tornó imprescindible para poder pagar los arriendos (Villafañe, 1938; Rutledge, 1987: 186). El caso de Mina Aguilar es coetáneo. En 1936 comenzaron las explotaciones por la National Lead Company. Los procedimientos de reclutamiento y contratación habrían sido similares a los de Pirquitas, pero por su ubicación en la ladera oriental de la sierra El Aguilar esta mina tuvo mayor influencia sobre la población de la Quebrada de Humahuaca (Salizzi, 2014).

Respecto a la expansión evangélica en la Puna, los creyentes de Jujuy indican que Juan Bautista Salva fue el primer evangelista:

\begin{abstract}
En el paraje El Cienego, departamento de Rinconada en la provincia de Jujuy por el año 1930 Juan Bautista cabalgando ebrio cayó al piso y durmió su borrachera. Al despertar observó como el viento le traía un papel. Era un folleto dejado en aquellas alturas. Lo leyó y lo volvió a leer al tiempo. Poco después, trabajando en un ingenio azucarero, en la zafra, conoció a un misionero quien le proveyó una Biblia. Por sugerencia de éste, se dirigió a la ciudad de San Salvador de Jujuy para asistir a la conferencia anual que se realizaba en la iglesia de calle Salta 950. Allí se convirtió al señor Jesucristo, regresando al Cienego donde fue corrido a tiros (Masciángelo, 2007: 104).
\end{abstract}

La evangelización en la puna fue consecuencia del tránsito humano que se habilitó entre los enclaves económicos. De acuerdo a los relatos orales, fue el misionero Thomas Easdale quién siguiendo los circuitos migratorios de los trabajadores de la zafra habría realizado los primeros viajes hacia la Quebrada de Humahuaca. Más adelante, con la extensión de los rieles hasta Abra Pampa y La Quiaca, y con la ayuda de mulas, los misioneros pudieron llegar a poblaciones puneñas de los departamentos de Rinconada y Cochinoca. Algunos especialistas indican que fue a partir de 1930 cuando los ingenios empezaron a tomar "campesinos de la Puna" como mano de obra. ${ }^{7}$ Otros indican que en 1924 el ingenio La Esperanza ya empleaba camiones para trasladar trabajadores collas en tramos que el ferrocarril no cubría (Sierra e Iglesias, 1998: 80). Así también, respecto a mina Piquitas González (2014) señala que los puneños debían pagar el arriendo de sus tierras trabajando no sólo para la mina sino también en el ingenio La Esperanza de los Leach, dueños parciales de la mina.

Debemos sumar a lo anterior el hecho de que en La Esperanza los misioneros actuaban al amparo de los Leach (Espinosa, 2017); en efecto, es posible suponer que estos primeros misioneros habrían tenido el beneplácito para hacer la obra como colportores y evangelistas en las zonas del altiplano adyacentes a mina Pirquita. También creemos que tempranamente habrían visitado mina El Aguilar puesto que allí oficiaba de médico Arturo Payne (Masciángelo, 2007: 108), hijo del pionero misionero irlandés Will Payne, reconocido como parte del movimiento Plymouth Brethren por aquellos que siguieron buena parte de sus pasos en el norte de Argentina y en diferentes regiones de Bolivia (Bisio, 1982). Los Payne y los Easdale eran familias misioneras amigas dentro de una amplia red de familias misioneras británicas emparentadas a lo largo y ancho del país.

Durante la primera mitad del siglo XX también estuvieron presentes misioneros canadienses que evangelizaron en el marco de la red de los Hermanos
7. "A partir de la década de 1930, los ingenios debieron compartir la oferta de mano de obra estacional indígena con los centros algodoneros; por lo tanto, buena parte de los indígenas chaqueños que trabajaban allí fueron reemplazados por campesinos de la puna" (Conti et al., 1989, citado por Bossert, 2012: 224). 
Libres. Se trataba de los misioneros Powell y Gerrard que habían llegado a la Argentina inicialmente para trabajar entre indígenas del Noroeste (Powell, 1998). Veamos un fragmento de una nota necrológica sobre Heriberto Gerrard:

En agosto de 1921 llegó a Argentina para trabajar con los indios del norte y en Bolivia. Viajó a Bolivia con don Reginaldo Powell a lomo de mula, pero el clima no le fue favorable y no pudo quedarse en ese país. Indudablemente tenía que ser para la Argentina./Se radicó en Jujuy donde permaneció "al pie del cañón" por 30 años y no hay localidad jujeña que no haya recibido el impacto del evangelio por la constante visitación de don Heriberto./ Su insistencia en viajar a Coranzuli en las altas cumbres jujeñas donde iba, parte en auto, parte a mula y parte a pie, fue posiblemente el principio de una afección cardiaca; pero eso a él no le importaba. En ese lugar tan inaccesible había hermanos que necesitaban una palabra de aliento y estímulo y solo a él le bastaba. ¡Había que ir!/ En 1959 se trasladó a Orán en la provincia de Salta, cumpliendo una meritoria obra hasta que el Señor lo llevó para su eterno descanso. (Clifford, 1972: 24-25).

Veamos un comentario más, escrito por un misionero llamado Walter Bevan:

Cuando llegué a la Argentina (1930), hace cuarenta años, fui casi directamente a la casa de los esposos Gerrard, en la ciudad de S.S. de Jujuy. [...] Don Heriberto me ayudó a practicar el idioma castellano, me llevó consigo en sus viajes, a veces a caballo, otras en tren o en su viejo Ford. Se hacían campañas con la carpa durante la zafra, visitas lejos en el bosque para pastorear a los humildes creyentes que allí vivían en sus ranchos, y visitas hasta el altiplano de las altas montañas. Fue en Tilcara que entregué mi primer breve mensaje en castellano, en presencia de don Heriberto./ Fue el "gran Corazón" del norte. ¡Cuánta gente he visto pasar por su casa! Enfermos, necesitados, hombres y mujeres de los lejanos valles y montañas, todos encontraron en él un consejero fiel y pastor amante (Bevan, 1972: 26).

Los canadienses, arribados hacia 1921, apoyaron la obra de los Easdale y las iglesias que los misioneros británicos habían fundado en las capitales de Jujuy y Salta. Desde allí se expandieron con mayor ahínco a la Quebrada de Humahuaca y a la Puna. Entre otras cuestiones las fuentes citadas evidencian que Powell y Gerrard no fueron estrictamente pioneros en evangelizar en tierras altas, donde ya existían familias evangélicas. También, de acuerdo al relato de los actuales creyentes y a lo indicado por Masciángelo (2007), entendemos que es sobre todo a partir de 1930 que se consolidó la presencia evangélica, especialmente en el pueblo de Coranzulí aproximadamente a $50 \mathrm{~km}$ de la mina Pirquitas, y a partir de allí hacia numerosos rincones del altiplano. Entre mediados de 1920 y 1950 los Powell y los Gerrard realizaron campañas evangelizadoras en la Puna, donde recibieron ayuda de los misioneros Walten Bevan, Ernesto Findlay y Thomas Easdale, entre otros (Masciángelo, 2007: 109).

A mediados de la década de1940, mientras las poblaciones afectadas por los ingenios azucareros empezaban a acceder a la tenue presencia de un Estado benefactor, en las tierras altas la situación fue diferente. Algunos historiadores indican que allí hubo un despertar de consciencias más acentuado en cuanto al reclamo de tierras. Es conocido el Malón de la Paz, grupo de indígenas andinos que partió desde Abra Pampa rumbo a la Capital Federal para entrevistarse con Perón. Poco después el Estado expropió tierras en la Puna y en parte de la Quebrada de Humahuaca, se suspendieron pagos de rentas y el reclutamiento de mano de obra. Sin embargo, hasta 1959 la propiedad de las tierras continuó 
en manos del Banco Nación (Rutlegde, 1987: 219-220). Un testimonio de la Puna señaló que "cuando vino Perón pusieron leyes nuevas. Hasta retretes les hicieron a los mineros porque no tenían, y al final los Leach han visto que de esa forma perdían plata, (entonces) empezaron a decir que ya no había más mineral y suspendió el trabajo" (Domínguez, 2002 en González, 2014: s/p).

Hacia la década de 1960, al tiempo que los ingenios conocen una nueva fase de mecanización que llevó a un declive en la demanda de mano de obra, la minería de las tierras tuvo un rol fundamental para la economía jujeña, aunque el pastoreo y la pequeña agricultura conservaron en la región un lugar central en términos económicos y culturales (Salizzi, 2014: 55). Esto es aún manifiesto, por ejemplo, en la comunidad indígena Casa Colorada, en su gran mayoría compuesta por familias evangélicas ubicada en el límite entre los departamentos Rinconada y Cochinoca, a más de 4000 m.s.n.m. En la actualidad dicha comunidad se dedica a la agricultura de subsistencia -usualmente en invernadero-,la cría de ganado -cabras y ovejas principalmente, vacas en muy menor medida- y la producción de derivados -carne seca, cueros, quesos, etc.- para la venta e intercambio. Antiguamente, se trataba de un grupo de viviendas que combinaban tales actividades con minería artesanal y producción de textiles, función principalmente masculina. En el primer cuarto del siglo XX, con el despegue de los Ingenios Azucareros y posteriormente de Mina Pirquitas, los varones de este grupo de hogares migraron estacionalmente para trabajar. Esto implicó transformaciones al interior del trabajo familiar y una diversificación en la estructura económica de subsistencia.

\section{Hacia una etnicidad evangélica}

En este apartado nos dedicaremos a ofrecer algunos aspectos que tienen en común las experiencias guaraníes y collas entre las misiones e iglesias de los Christian Brethren o Hermanos Libres, y que en relación con los contextos sociohistóricos ya expuestos nos darán una idea más completa del escenario que fundamenta nuestro argumento principal. Como hemos dado cuenta en otra oportunidad, fue característico de este grupo de misioneros británicos la propagación de mediaciones relativas a la cultura escrita: la biblia, porciones del evangelio, tratados, folletos, himnarios, devocionales, etc. De tal modo, los indígenas fueron impulsados a tomar contacto con estas tecnologías y, de diverso modo, a una apropiación de la cultura escrita. En esta dirección, actuales creyentes de la Esperanza que hoy promedian 80 años recuerdan a los misioneros como maestros rigurosos y cuentan que aprendieron a leer y escribir en la misión antes que en la escuela. ${ }^{8}$

Pero la cultura misionera no se restringía al llamado ministerio de la escritura. Las reuniones de culto promovidas por los misioneros eran acompañadas de alabanzas caracterizadas tanto por el uso himnario británico como del velo en las mujeres -para cubrir su cabellera. El himnario fue traducido del inglés al español muy tempranamente; en 1927 la imprenta editorial de Quilmes de los Hermanos Libres publicó una segunda edición de este libro -desconocemos cuando fue la primera- y en 1950 ya existía una quinta edición. A lo largo del siglo XX los Hermanos Libres no dejaron de publicar y distribuir este libro, no sólo en Argentina sino también en países limítrofes. Con continuidades y rupturas en cuanto al significado de estos objetos, a lo largo de las iglesias guaraníes y collas que hemos visitado hemos advertido su presencia (Espinosa, 2018).
8. Para una etnografía de la cultura escrita presente en las interacciones entre los misioneros Hermanos Libres y grupos indígenas del Noroeste argentino, más precisamente entre grupos guaraníes y collas de Salta y Jujuy, consúltese Espinosa (2018). 


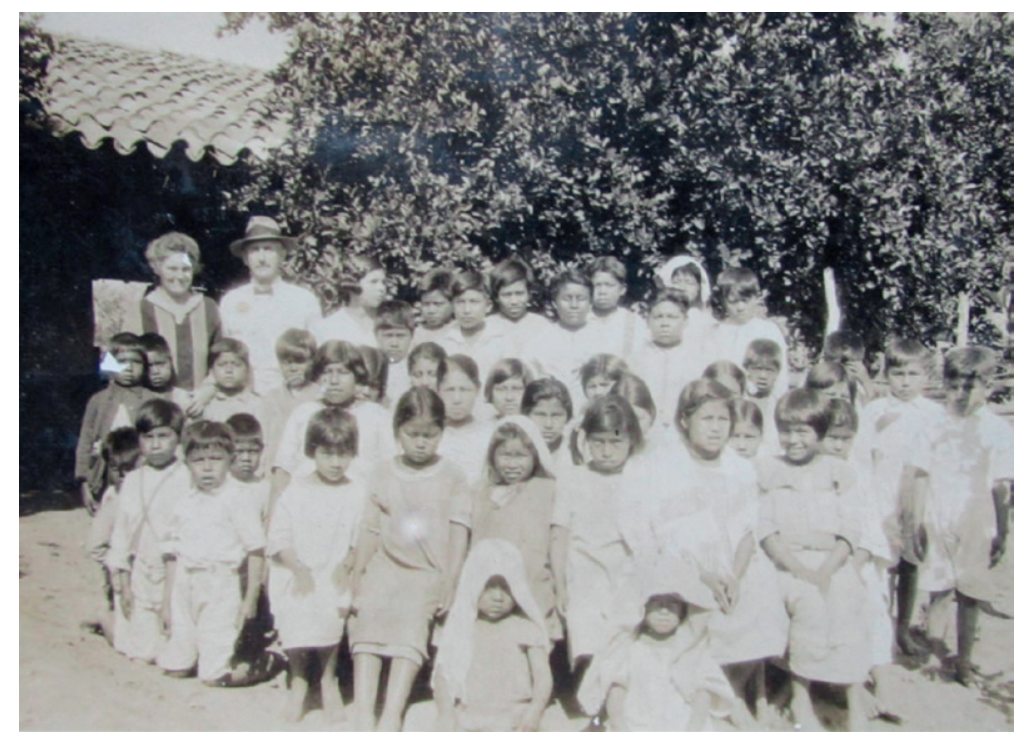

Imagen 1. Mujer de identidad desconocida, Thomas Easdale y un grupo de niñas y niños suponemos que en La Esperanza o en Urundeles, circa 1930-1940. Fuente: Archivo personal de Allan Easdale.

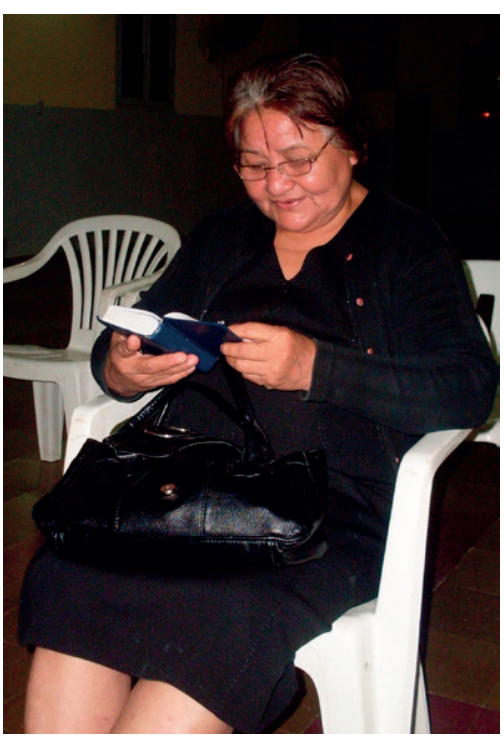

Imagen 2. Mujer guaraní cantando con himnario en mano, "Misión Cherenta" de Tartagal, 2013. Fuente: propia.
9. El espacio de un artículo no nos permite profundizar en este asunto. Como ejemplo del tipo de fenómeno que implicaron las conferencias de los Hermanos Libres a lo largo y ancho del país compartimos una nota de 1960 de la revista evangélica El Sendero del Creyente: "No es poca la influencia que han tenido las conferencias en la vida y crecimiento de las iglesias, y su ponderación bien vale tomarla en consideración, ellas han servido de nexo inapreciable para mantener la unidad y comunicación de las mismas y la coordinación del trabajo en todo el país; han sido un factor de estímulo para los creyente, y la enseñanza suministrada en ellas ha constituido una de las principales fuentes en que han bebido los mismos y han fortalecido su fe. Pero no sólo la plataforma ha sido lo importante de las conferencias: la convivencia de esos días, las mesas tendidas para el almuerzo o el té en común llenas de bullicio y gozo cristianos, las excursiones o picnics celebrados en alguna de ellas con sus cerrillos apartados, por un lado bullangueros grupos juveniles, por otro consejos de reposados ancianos; la mesa familiar compartida con los visitantes, el hogar abierto de par en par y sin reservas para los hermanos; en fin, todo creando una atmósfera propicia y saludable que ha influido y afectado de manera provechosa y trascedente la obra de nuestro medio" (EI Sendero del Creyente,1960,1: 29).

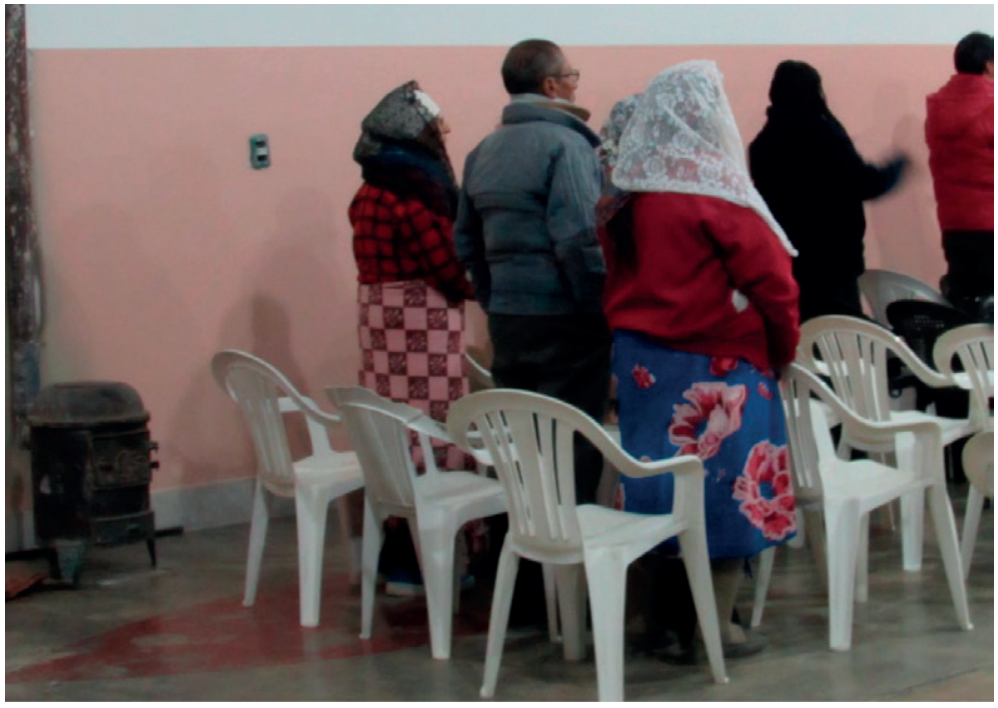

Imagen 3. Mujeres andinas con velo en Abra Pampa, 2018. Fuente: propia.

Entre los rituales más comunes que aún se conservan podemos mencionar las Conferencias. Se trata de reuniones de, al menos, tres días que desde 1910 los Hermanos Libres realizan a lo largo y ancho del país. Existen conferencias nacionales, provinciales y regionales, usualmente organizadas en fechas patrias -como el 25 de mayo o el 9 de julio-, o de la liturgia católica -como Semana Santa. En el caso de las conferencias protagonizadas por los y las indígenas se trata aún de verdaderos mítines evangélicos, en donde familias guaraníes de Jujuy y Salta se encuentran. Así también en la Puna, familias de diferentes comunidades, usualmente emparentadas, se reúnen para compartir unos días. ${ }^{9}$

Un aspecto conspicuo del proceso de misionalización de los Hermanos Libres en la Argentina fue el énfasis en la conversión de familias completas. Esta tendencia -que bien podría apenas justificarse por la máxima bíblica de evitar el yugo desigual- era homóloga al hábito que los misioneros adquirieron en 


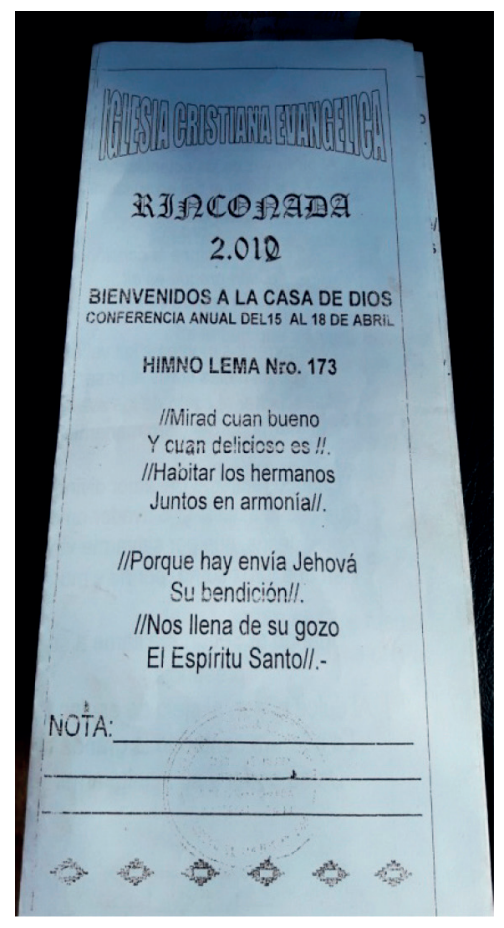

Imagen 4. Folleto de una Conferencia en Rinconada, 2010.

territorio misionero. El caso de los Hermanos Libres fue distinto al modelo de la South American Mission Society, en donde a los misioneros designados por la agencia los acompañaba un enfermero, un maestro, etc., además del hecho de que estos eran agentes profesionales con un salario para dicha tarea. Las obras misioneras y las iglesias de los Hermanos Libres estaban a cargo de un matrimonio misionero, usualmente emparentado con otros matrimonios que misionaban en territorios distintos. Dicha red misionera familiar se configuró de un modo simple. Primero llegaban varones solteros; después mujeres que eran mayormente hermanas o hijas de algún misionero en ejercicio; al llegar a Argentina se casaban con los misioneros solteros o viudos. Alguna de estas mujeres eran maestras o enfermeras pero, más allá de sus oficios, de acuerdo a las memorias de los creyentes ellas cumplían funciones centrales en el campo misionero, aunque las fuentes apenas las recuerden como esposas y nos priven de sus nombres (Espinosa, 2014).

En la investigación que llevé adelante con familias evangélicas de origen sirio en Santiago del Estero observé que las primeras familias conversas también operaron en la configuración de una red de familias emparentadas, cuyos miembros varones destacados posteriormente constituyeron un cuerpo de especialistas religiosos, llamados ancianos y sobreveedores, que se ocupó de la gestión espiritual y material de cada iglesia o asamblea en la provincia y en otras del Noroeste, como Tucumán y Jujuy -en donde a principios de siglo hubo una inmigración árabe considerable. Este cuerpo de especialistas era crucial para la supervivencia de cada nueva comunidad de creyentes. Puesto que, respondiendo a su ética de origen y a la no dependencia de una iglesia centralizada y jerarquizada que sostuviera misiones e iglesias fuera de Gran Bretaña, los misioneros Hermanos Libres buscaban con ahínco formar congregaciones relativamente autónomas. Bajo la máxima protestante del libre sacerdocio evitaban la formalización de cargos, aunque fomentaban el liderazgo de un cuerpo de ancianos y sobreveedores encargados de aspectos cultuales, espirituales y administrativos. Esto implicaba un atractivo para grupos sociales que 
simultáneamente buscaban la integración a la nación y una relativa autonomía que permitiera la auto-regulación y preservación del grupo social. Así, sumado al hecho de la tendencia al connubio al interior del mismo grupo étnico y evangélico, en definitiva el culto permitió la conformación de una comunidad etno-evangélica (Espinosa, 2014).

Ahora bien, ¿cómo fue la situación con las poblaciones guaraníes del piedemonte y collas del altiplano? Las fuentes y las memorias de actuales pobladores de La Esperanza nos informan que los misioneros también hacían un largo trabajo entre familias. En la década de 1940 no sólo existía una gran comunidad denominada Cherenta en el ingenio y otras en cercanías, sino que además había evangelistas guaraníes alfabetizados y músicos pertenecientes a las primeras familias conversas. Casasola, Panyagua, Arias, Arroyo y Flores figuran entre los apellidos con mayor protagonismo y que se desplazaban junto a los misioneros extranjeros y por cuenta propia entre los lotes San Antonio, El Puesto, Arrayanal, Parapeti -del Ingenio La Esperanza-, Maíz Negro, Paulina, Alto Talar -del Ingenio Ledesma-, El bananal, Perico, Finca los Lachapos y entre localidades de la provincia de Salta (Espinosa, 2017).

Fenómeno similar observamos en la Puna. De acuerdo a los relatos de nuestros interlocutores puneños sabemos que en Coranzulí se convirtieron las familias Puca, Cruz Llampa y luego las familias Calpaychay y Mamamí. Representantes de estas familias luego llevaron el evangelio a Mina Pirquita, Coyahuayma, Casa Colorada, El Toro, Abra Pampa, Mina Aguilar, Barrancas, Rinconadas, Tres Pozos y Catua; posteriormente a Paycone, Lagunillas del Farallón y Olaróz. En mi etnografía también registré los apellidos Calpaychay, Cruz Llampa, Puca y Alancayentre de los líderes con mayor antigüedad y autoridad en las iglesias de Tilcara, Abra Pampa y Casa Colorada. Registramos que estas familias llevan entre tres y cuatro generaciones como evangélicos.

En la actualidad las familias originarias mencionadas para cada subregión se reconocen evangélicas o creyentes y se relacionan entre ellas a través de vínculos de parentesco. Además, los apellidos referidos predominan entre los consejos de anciano -o pastores-, como se denomina a los líderes socio-religiosos en las iglesias de los Hermanos Libres. Al igual que en el caso sirio-evangélico estudiado en Santiago del Estero, este consejo de ancianos está a cargo no sólo de los designios espirituales del grupo sino que también constituye una autoridad de tipo comunal entre las familias indígenas evangélicas. En efecto, entendemos que en contextos de hostilidad -pasada y presente- para las poblaciones indígenas, la nueva religión deviene en la posibilidad de una relativa autonomía socio-política y en la preservación del grupo social.

Un párrafo aparte merece el lugar de la Iglesia Católica en las representaciones de los actuales guaraníes y collas evangélicos. Recordemos que el actual Noroeste Argentino constituyó la antigua Gobernación del Tucumán, donde el catolicismo prosperó durante tres siglos de conquista y colonización. Aunque inicialmente los misioneros Hermanos Libres en su carácter de británicos tuvieron mayores salvoconductos, la situación de los indígenas estuvo marcada por la subordinación de hecho -dada su condición de mano de obra barata en los enclaves económicos- y por las representaciones dominantes impregnadas de racismo. En el caso de los actuales creyentes guaraníes de La Esperanza observé la autoafirmación de sus identidades en contraposición con los criollos católicos de San Pedro. En cuanto a mi reciente trabajo de campo en la Puna, encontré a varios interlocutores ensalzarse con la pertenencia evangélica en 
tanto electiva, en contraposición de la católica producto de la imposición colonial, según hemos tomado nota.

Con lo relatado hasta aquí, ¿en qué medida es posible interpretar que el cambio religioso vehiculizó antes una nueva etnicidad que una des-etnización? Para dar una respuesta completa es preciso retomar algunos de los elementos socio-histórico y de la evidencia etnográfica expuestos y los elementos teóricos adelantados en la primera parte. Para ello, inspirados en cómo Erik Langer (2009) ordena las causas de las migraciones de chiriguanos del Oriente boliviano hacia los ingenios del Noroeste argentino, podemos agrupar los elementos que de algún modo intervinieron en la adopción del evangelismo por parte de estos grupos en la primera mitad del siglo XX en factores push (presión, empuje) y pull (atracción).

\section{Factores push}

a) Los ingenios azucareros sometieron a guaraníes y collas a un régimen laboral inter-étnico y jerárquico basado en prácticas de explotación y representaciones de racialización, fundamentadas en principios civilizadores y patrones culturales externos. Por su parte, los establecimientos mineros desarticularon las economías puneñas y presionaron a los indígenas de la Puna a pagar abusivas sumas por el arriendo de sus tierras, única vía para persistir con las economías ganadero-labradoras. Sin duda, la hostilidad del trabajo capitalista abonó el camino hacia la búsqueda de espacios sociales menos severos; las misiones e iglesias evangélicas situadas a un paso de las explotaciones azucareras y mineras fueron una alternativa en ese sentido.

b) En el plano cultural, el arquetipo de Nación supuso un proceso de segregación y racialización de las diferencias culturales de la población originaria, mestiza, criolla e inmigrante. Acceder a la ciudadanía argentina implicaba, primero la negativa sorpresa de saberse un otro despreciado desde un ideal de persona blanca, europea y cristiana y, posteriormente, la presión para inhibir los marcadores de esas diferencias (Segato, 2007a). Al igual que con las explotaciones de los enclaves económicos, este contexto favoreció la adopción de alternativas identitarias como la evangélica pues, como concluiremos más adelante, las mismas albergaban una doble naturaleza: por un lado, eran globalmente aceptadas por sus elementos civilizantes; por el otro, habilitaban la producción social del grupo en diferentes grados.

c) Si bien la ideología liberal y la modernización económica de la Argentina de fines del siglo XIX y principios del siglo XX favorecieron la expansión evangélica de esta corriente británica sobre territorios del Noroeste Argentino, tras tres siglos de conquista y colonización el culto católico conservó en los hechos su carácter oficial entre las elites y la mayor parte de la sociedad criolla, relegando otras expresiones religiosas a una condición de minorías. Como informa la etnografía, la identificación evangélica indígena parece haber estado teñida -incluso hasta hoy- de sentimientos de oposición al predominio católico entre las capas dominantes y en la sociedad envolvente.

\section{Factores pull}

a) En estos contextos de explotación laboral y violencia simbólica, la cultura misionera promovida por los misioneros constituyó un polo de atracción para 
los grupos indígenas. Aunque aquí no hemos profundizando, importante es destacar la incorporación a la cultura escrita que se promovía en las misiones e iglesias de los Hermanos Libres. Si bien constituía una exigencia desde el punto de vista civilizador también era una tecnología necesaria para lidiar mejor con los desafíos y obstáculos de la nueva sociedad. Pero la cultura misionera iba más allá de la escritura, la promoción de reuniones de culto, de la mano de himnos y coros evangélicos, y las llamadas conferencias complementaban un eficaz torrente emocional e identitario. Además de activar cohesión y pertenencia en contextos hostiles, la cultura misionera fue una herramienta simbólica para contornear la estigmatización racial adjudicada.

b) La máxima evangélica de evitar el yugo desigual coadyuvó a sostener alianzas entre familias del mismo grupo cultural. Como hemos esbozado más arriba, es posible decir que entre las actuales familias guaraníes y collas evangélicas de mayor antigüedad -entre las cuales existen al menos tres generaciones- se hallan relaciones de parentesco en algún grado con otras igualmente antiguas en la religión. En efecto podemos afirmar que por motivos religiosos existió una endorreproducción (Weber, 1964), caracterizada por relaciones de parentesco agnaticio, endogamia en el nivel comunitario -por lo que estas familias están emparentadas entre sí- y exogamia con familias de otras comunidades étnicas -guaraníes, colla- y evangélicas de la misma denominación.

c) Las iglesias de los Hermanos Libres también eran llamadas asambleas debido a la búsqueda de una eclesiología asamblearia, libre de jerarquías y cargos ministeriales formalizados exteriormente. Aunque en la práctica se conformó un cuerpo de ancianos que monopolizaba el capital religioso, no es menos cierto el hecho de que estas asambleas cristianas se independizaron de la tutela misionera y forjaron mecanismos de auto regulación y administración. Esto devenía en la posibilidad de cierta autonomía socio-política mediante la nueva religión. A diferencia del caso sirio-evangélico señalado más arriba, este aspecto adquirió otro relieve en las iglesias evangélicas indígenas. Usualmente emplazadas en zonas rurales y periurbanas, donde las divisiones de esferas de la vida social no eran ni son tan tajantes, la cultura misionera influyó en las formas de organización social y política, lo que puede vislumbrase en la robustez de los liderazgos salientes de las primeras familias conversas.

En el primer apartado sugerí que el encuentro o interacción de las poblaciones guaraníes y collas con una nueva religión operó sobre un proceso de des-indianización y hacia la configuración de una etnicidad evangélica. En el análisis de elementos descritos es posible terminar de delinear esta idea. Para ello es preciso remarcar nuevamente que la distinción de factores push \& pull es analítica y que estos deben contemplarse en su ineludible relación contextual.

En efecto, la configuración de factores push presionó en mayor medida a los grupos indígenas a la adopción de la propuesta evangélica en un movimiento de des-racialización o des-indianización. En tanto, las acciones y los imaginarios civilizatorios que impusieron categorías esencializantes de sus diferencias culturales buscaban naturalizar una posición subordinada y de tolerancia a la violencia capitalista y estatal; la opción menos severa, en términos civilizatorios, de la propuesta evangélica fue una alternativa a mano para inhibir o correrse de esas marcaciones negativas. Recordemos que guaraníes y collas estaban en una mejor posición que otros grupos étnicos, como los de la región chaqueña, en la estratificación que impusieron las miradas dominantes del periodo pues a priori su condición, en todo caso, era menos primitiva pero primitiva al fin. 
En la combinación de factores pull se dinamizaron posibilidades para dar continuidad al grupo social. Guaraníes y collas encontraron condiciones para la reproducción social del grupo en un nuevo sistema social y político, en una configuración cultural relativamente autónoma de las estructuras de poder de la sociedad envolvente. Sobre todo, es en la adopción de una cultura misionera impregnada de rituales, tecnologías y saberes para lidiar con el mundo moderno en dónde encontramos a lo religioso, siguiendo a Weber (1964), como motivación para la creación de sentimientos de afinidad étnica. En suma, en la combinatoria de factores pull encontramos elementos constitutivos de una etnicidad evangélica. No obstante, es en la dinámica relacional entre factores de presión y de atracción donde el argumento se completa: la adopción de la propuesta evangélica como forma de inhibir marcas negativas -movimiento de des-indianización- y como agencia tendiente a dar continuidad al grupo social bajo el marco de una etnicidad evangélica, que no excluye la pertenencia guaraní o colla sino que permite una reelaboración productiva.

Como formación cultural resultante de interacciones entre indígenas y misioneros, la etnicidad evangélica es particularmente significativa en el marco relacional de los factores expuestos, especialmente activados durante la primera mitad del siglo XX. Si bien la etnografía nos informa de elementos que a la luz de las fuentes y la bibliografía disponible redunda en el argumento aportado -des-indianización y etnicidad evangélica-, el objetivo del presente artículo estuvo orientado a trazar el proceso de configuración de identidades etno-evangélicas, categoría que en sus términos remarca el dinamismo de una formación identitaria que no negativiza la pertenencia indígena.

Desde las últimas décadas del siglo XX, asistimos a la emergencia de movimientos de etnogénesis, causa y efecto de nuevas legislaciones para los derechos de los pueblos originarios. En este contexto la etnicidad evangélica entra en tensión con algunos agrupamientos neo-indigenistas demandando alguna forma de inclusión, tanto desde su reivindicación de pertenencia indígena como reclamando el derecho al pluralismo religioso al interior de la gran comunidad guaraní y colla. El estudio del desarrollo o reconfiguración actual será objeto de futuro trabajos.

\section{Palabras finales}

En el presente artículo quisimos realizar un aporte desde múltiples perspectivas: histórica, etnográfica y comparativa. Dada la ausencia de investigaciones académicas sobre el pasado evangélico en el Noroeste Argentino -las escasas fuentes documentales disponibles en alguna medida fueron suplidas con el recurso etnográfico-, nuestras investigaciones procuraron ahondar epistemológicamente en la relación entre historia y etnografía (cfr. Espinosa, 2018). En este sentido, creemos que la mirada comparativa aquí propuesta merece un comentario adicional.

Acordamos con Balbi (2017) cuando advierte la tendencia contemporánea a reducir la antropología a la etnografía, como así también la limitación de la productividad de la etnografía cuando es concebida antes como descripción que como análisis. Como ya planteaba Boas desde inicios del siglo XX, los hechos sociales varían al interior y entre culturas y no es menos cierto que presentan continuidades e invariancias. De tal manera, en el presente trabajo buscamos articular analogías y contrastes entre universos empíricos distintos; intentamos reconstruir contextos significativos, complejos y productivos, lo 
que constituyó el corpus de información y los procedimientos básicos para realizar una interpretación sustantiva y generalizable sobre la relación entre etnicidad y religión. Como indica Balbi (2017), cierta resistencia a la comparación y la generalización obedece a una comprensión pobre de la teoría social, a una inconsistencia epistemológica que relega la antropología a un nivel meramente ideográfico, algo que modestamente intentamos revertir.

En este trabajo trazamos puentes entre realidades que desde el sentido común y docto son muy difíciles de integrar. Para visualizar los costos de vincular lo indígena y lo evangélico, el piedemonte -las yungas- y la Puna, es decisivo repensar las tradiciones intelectuales en las que pueden validarse esta clase de esfuerzos. Las investigaciones sobre evangelismos indígenas en la Argentina se han concentrado en la región chaqueña. Integradas a la Etnografía Chaqueña, verdadera subdisciplina, contribuyen a un campo de estudio auto-centrado. Para los especialistas del Noroeste Argentino, dominado por historiadores y etnohistoriadores, las misiones e iglesias evangélicas del siglo XX forman un referente esquivo, por la escasez de fuentes disponibles o por las dificultades para su acceso. Finalmente, la sociología de la religión sobre grupos evangélicos centró su atención en el pentecostalismo y neopentecostalismo. La mayor parte de los trabajos empíricos se focalizan en áreas metropolitanas. Lejos de atribuir responsabilidades, considero que las estructuras -de los temas investigados, de las disciplinas que nos abarcan, de toda dinámica social- solo son revelables en los bordes de los sistemas socio-culturales, en las contradicciones categoriales que revelan la complejidad de lo indígena, de lo religioso o de cualquier adscripción identitaria. Con esta advertencia sobre el estado de las especializaciones, y en la estela de lo demostrado en este trabajo, consideramos en extremo paradójico que la etnología actual considere las adscripciones religiosas como un dato marginal. Se desprende que los avances de la ciencia no sólo se gestan en el descubrimiento de nuevos conjuntos factuales sino que precisan imperiosamente del tratamiento reflexivo sobre las propias fragilidades y obstáculos en un panorama de especializaciones que lamentablemente tiende cada vez más a la fragmentación.

\section{Agradecimientos}

Quisiera dedicar este trabajo a la memoria de Gabriel Casasola (QEPD), guaraní, evangélico, músico, de saberes profundos y corazón abierto, quien colaboró con nosotros a lo largo de varios años de trabajo de campo. 


\section{Q Bibliografía}

》 Balbi, F. (2017). “Servidumbre y emancipación de la comparación” en Balbi, F. (comp.); La comparación en Antropología social: problemas y perspectivas: 29-71. Buenos Aires, Editorial Antropofagia.

» Barth, F. (1976). "Introducción” en Barth, F. (ed.); Los grupos étnicos y sus fronteras. La organización social de las diferencias culturales: 9-49. México DF, Fondo de Cultura Económica.

》 Bevan, W. T. (1972). ¿Quién tomará su lugar? El Sendero del Creyente 1: 26.

"Bianchi, S. (2004). Historia de las religiones en la Argentina. Las minorías religiosas. Buenos Aires, Editorial Sudamericana.

» Bisio, C. (1982). Nuestros Primeros Pasos. Buenos Aires, Librería Editorial Cristiana.

" Bossert, F. (2012). "Notas sobre la jerarquía interétnica en los ingenios del noroeste argentino" en Villar D. e I. Combés (eds.); Las tierras bajas de Bolivia: miradas históricas y antropológicas: 217-238. Santa Cruz de la Sierra, Editorial el país.

" Campi, D. (1992). Estudios sobre la historia de la industria azucarera Argentina. II. San Miguel de Tucumán. San Miguel de Tucumán, Unidad de Investigación en Historia Regional UNJu, Ediciones del Gabinete/ Secretaría de post-grado, Universidad Nacional de Tucumán.

"Catoggio, M. S. (2008). "Gestión y regulación de la diversidad religiosa en la Argentina” en Mallimaci, F. (coord.); Religión y política: 105-116. Buenos Aires, Biblos.

" Ceriani Cernadas, C, y A. López (2017). "Introducción. Una antropología comparativa sobre las misionalizaciones chaqueñas" en Ceriani Cernadas, C. (dir.); Los evangelios chaqueños. Misiones y estrategias indígenas en el siglo XX:19-36. Buenos Aires, Asociación Rumbo Sur.

》 Comaroff, J. \& J. Comaroff (1992). Ethnography and the Historical Imagination. Boulder, Westview Press.

" Combés, I. \& T. Saignes (1991). Alter Ego Naissance de l'identité chiriguano. Paris, Editions de l'École des Hautes Études en Sciences Sociales.

»Clifford, J. (1972). “Con el Señor”. El Sendero del Creyente 1: 24-26.

»Espinosa, M. (2014). “Identidad evangélica, linajes y trazos étnicos: los Hermanos Libres en Santiago del Estero". Tesis doctoral en Antropología, Facultad de Filosofía y Letras, Universidad de Buenos Aires.

"Espinosa, M. (2017). Misiones evangélicas, capitalismo y regulación estatal entre los guaraníes del Noroeste Argentino. Revista del Museo de Antropología 10 (2): 193-205.

»Espinosa, M. (2018). El ministerio de la escritura: expansión evangélica y mediación cultural entre indígenas del Noroeste Argentino. Ciências Sociais e Religião 20: 158-179.

" Frigerio, A. (2007). "Repensando el monopolio religioso del catolicismo en la Argentina" en Carozzi, M. J. y C. Ceriani Cernadas (coords.); Ciencias sociales y Religión en América Latina. Perspectivas en debate: 87-114. Buenos Aires, Biblos.

" González, N. (2014). Política y minería en la puna jujeña. Mina Pirquitas, Jujuy, Argentina. III Jornadas Nacionales sobre estudios regionales y mercados de trabajo. San Salvador de Jujuy, Universidad Nacional de Jujuy/ Red SIMEL. Disponible en Internet: https:// www.aacademica.org/iii.jornadas.nacionales.sobre.estudios.regionales.y.mercados. de.trabajo/47. Consultada el: 3 de noviembre de 2019. 
" Hirsch, S. (2004). “Mbaporenda: el lugar donde hay trabajo. Migraciones guaraníes al Noroeste argentino". Etnohistoria. Disponible en Internet: http://etnohistoria. equiponaya.com.ar/htm/o4_articulo.htm. Consultada el: 9 de octubre de 2018.

" Lagos, M. (1992). “Conformación del mercado laboral en la etapa de despegue de los ingenios azucareros jujeños (1880-1920)" en Campi, D. (comp.); Estudios sobre la historia de la industria azucarera Argentina (II): 51-90. San Miguel de Tucumán, Ediciones del Gabinete/ Secretaría de post-grado, Universidad Nacional de Tucumán.

" Langer, E. (1995). "Missions and frontier economy: the case of the Franciscan missions among the chiriguanos, 1845-1930" en Langer, E. \& R. Jackson (comps.); The new Latin American mission history: 49-75. Lincoln/ Londres, University of Nebraska Press.

» Langer, E. (2009). Expecting Pears from an Elm Tree: Franciscan Missions on the Chiriguano Frontier in the Heart of South America, 1830-1949. Durham NC, Duke University Press.

»Lozano, C. (2001). Misioneros cristianos y población con raíces indígenas: un debate sobre la identidad y las diferencias en el noroeste argentino. Berlin, Wissenschaftlicher Verlag.

» Masciángelo, G. (2007). Inicios del evangelio en la Quebrada y Puna Jujeña en Bisio, C. (comp.); Congregados en su nombre: 103-112. Buenos Aires, Librería Editorial Cristiana.

» Montero, P. (org.). (2006). Deus na aldeia. Missionários, índios e mediação cultural. São Pablo, Editora Globo.

» Nordenskiöld, E. ([1912] 2002). La vida de los indios. El Gran Chaco (Sudamérica). La Paz, APCOB/Plural.

»Palomeque, S. (2000). “El mundo indígena. Siglos XVI-XVIII” en Tándeter, E. (dir.); Nueva Historia Argentina. La sociedad colonial (2): 87-144. Buenos Aires, Sudamericana.

» Powell, D. (1998). La historia que faltaba. El protestantismo en Tucumán. Buenos Aires, Instituto de Historia y Pensamiento Argentinos/ Editorial Kairós.

" Rutledge, I. (1987). Cambio agrario e integración. El desarrollo del capitalismo en Jujuy: 1550-1960. Tucumán, ECIRA/CICSO.

"Salizzi, E. (2014). “Gran minería” y transformaciones regionales en la Puna jujeña: el caso de la mina Aguilar (1936-1990). Estudios del NOA 13: 47-66.

»Santamaría, D. (1992). “Migración laboral y conflicto interétnico. El caso de los migrantes indígenas temporarios en los ingenios saltojujeños” en Campi, D. (ed.); Estudios sobre la historia de la industria azucarera Argentina II: 91-112. San Miguel de Tucumán, Ediciones del Gabinete/ Secretaría de post-grado Universidad Nacional de Tucumán.

» Segato, R. (2007a). “Cambio religioso y des-etnificación: la expansión evangélica en los Andes Centrales de Argentina” en Segato, R. (ed.); La Nación y sus Otros: raza, etnicidad y diversidad religiosa en tiempos de políticas de la identidad: 243-272. Buenos Aires, Prometeo.

»Segato, R. (2007b). “Formaciones de alteridad: Nación y cambio religioso en el contexto de globalización” en Segato, R. (ed.); La Nación y sus Otros: raza, etnicidad y diversidad religiosa en tiempos de políticas de la identidad: 175-202. Buenos Aires, Prometeo.

» Segato, R. (2007c). “Una vocación de minoría: la expansión de los cultos afro-brasileros en la Argentina como proceso de re-etnización” en Segato, R. (ed.); La Nación y sus Otros: raza, etnicidad y diversidad religiosa en tiempos de políticas de la identidad: 243-272. Buenos Aires, Prometeo.

» Semán, P. (2006). Bajo continuo. Exploraciones descentradas sobre cultura popular y masiva. Buenos Aires, Editorial Gorla.

» Sierra e Iglesias J. P. (1998). Un tiempo que se fue. Vida y obra de los hermanos Leach. San Salvador de Jujuy, EDUNJU. 
»Teruel, A. (2005). Estructuras agrarias comparadas: la Puna argentina y el sur boliviano a comienzos del siglo XX. Mundo Agrario 6 (11). Disponible en Internet: http://www. memoria.fahce.unlp.edu.ar/art_revistas/pr.545/pr.545.pdf Consultada el: 3 de noviembre de 2019.

» Teruel, A. y R. Gil Montero (1996). Trabajo familiar y producción de textiles en las tierras altas de la provincia de Jujuy. Mediados del siglo XIX. Revista Andina 1: 197-222.

»Villafañe, B. (1938). El asesinato de Rafael Tauler. Perpetrado por las autoridades y amparado por la justicia. Un drama del far-west en la puna de Jujuy. La situación de Jujuy. Una vergüenza nacional. Buenos Aires, Imprenta Mercatali.

"Von Rosen, E. (1957). Un mundo que se va: Exploraciones y aventuras entre las altas cumbres de la cordillera de los Andes. San Miguel de Tucumán, Fundación Miguel Lillo, Universidad Nacional de Tucumán.

»Weber, M. (1964). Economía y Sociedad. México DF, Fondo de Cultura Económica.

» Wright, P. (2002). “L’Evangelio’: pentecôtism e indigène dans le Chaco argentin”. Social Compass 49 (1): 43-66. 